\title{
Effects of sub-lethal gamma irradiation on antibiotic susceptibility profile and population dynamics of Enterococcus faecalis and Escherichia coli in water
}

\author{
A.O. Ogunniran ${ }^{1}$, O.M. David ${ }^{2 *}$, M.O. Isinkaye ${ }^{3}$ and A.K. Olawale ${ }^{4}$ \\ ${ }^{I}$ Department of Science Laboratory Technology, Ekiti State University, Ado-Ekiti, Nigeria \\ ${ }^{2}$ Department of Microbiology, Ekiti State University, Ado-Ekiti, Nigeria, \\ ${ }^{3}$ Department of Physics, Ekiti State University, Ado-Ekiti, Nigeria \\ ${ }^{4}$ Department of Biological Sciences, Afe Babalola University, Ado-Ekiti, Nigeria. \\ *Correspondence (david.oluwole@eksu.edu.ng) \\ (iD) http://orcid.org/0000-0002-0465-6950
}

\begin{abstract}
Disinfection of water is important in the control of waterborne diseases. It is used to kill or inactivate microorganisms in a gradual process that involves a number of physical-chemical and biochemical processes. The effects of sub-lethal gamma irradiation on survival and resistant pattern of two indicator organisms used in assessing water quality: Enterococcus faecalis and Escherichia coli were investigated in this study. Plate count agar and disc diffusion methods were used to determine the load and antibiotics susceptibility pattern of the test organisms respectively before and after exposure to different doses of gamma irradiation in sachet water samples. Survival pattern of the two indicator organisms to gammaray showed a decline in the populations of the organisms with time compared to the controls (non-radiated). The effect of the irradiation on the E. coli was dose dependent, it initially responded to the effects of the irradiation in the first 4 days of exposure compared to the control. On exposure to 4 and 5 gy gamma rays a minimum population was reached on the $7^{\text {th }}$ day. At $\mathrm{p}<0.05$ the population of $E$. coli was significantly different from the control. The survival pattern of Ent. faecalis also followed a similar growth pattern. The application sub-lethal gamma irradiation did reduce the population of the isolates and also affect the antibiotic susceptibility of the isolates.
\end{abstract}

Keywords: Enterococcus faecalis, Escherichia coli, Gamma irradiation, Population, Water.

\section{INTRODUCTION}

Water disinfection reduces the incidence of water-borne infections and lowers the rate of morbidity and mortality among infants and immunocompromised individuals. Chemicals like chlorine, chlorine dioxide, ozone, and irradiations are common mainly used in the treatment of drinking and wastewater (Akelah 2013; Ambulkar 2015). These chemical and physical agents kill and/or inactivate microorganisms (Akelah 2013). Irradiation has been reported to kill and inhibit the growth of pathogens like Escherichia coli, Salmonella, Listeria, Shigella and Campylobacter jejuni (Rothkamm 2003; Kelly 2005; Ansari 2009; Sharon Palmer 2009).

Escherichia coli is a Gram-negative rod of which the natural habitat is the intestinal tract of humans and animals (Farmer 2003). Due to its presence in faeces, its detection in drinking water, foods, recreational water etc. is regarded as an indicator of faecal pollution. When found in water bodies in levels exceeding one or more cells in $100 \mathrm{~mL}$ of water, the water is regarded as not safe for consumption. Enterococcus faecalis has also been identified as an indicator of faecal contamination (Jin et al. 2004). In the European Union (EU), enterococci are used to monitor microbial quality of water. Unlike coliform, enterococci are not permitted in $100 \mathrm{~mL}$ and in $250 \mathrm{~mL}$ drinking water samples from tap and bottled water respectively (CEU 1998). The U.S. Environmental Protection Agency (EPA) has also approved enterococci in place of faecal coliform bacteria as the preferred indicator of faecal pollution and health risk in marine water (Mote et al. 2012). Both E. coli and Ent. faecalis are released through faeces of warm-blooded animals, including human beings (Wheeler et al. 2002).

Having short wavelength and high penetrating power resulting from the nuclear disintegration of certain radioactive substances such as Cobalt 60 and Cesium 137 gamma radiation is the most energetic form of electromagnetic radiation (Gross 2007). Ionizing radiation can be defined as radiation that has sufficient energy to remove electrons from atoms and molecules and to convert them to electrically-charged particles called ions (Abo-State et al. 2014). Three types of 
damage in DNA are known to be induced by gamma rays and they are: single-strand breaks, double strand breaks and, nucleotide damage, which include base damage and damage in the sugar moiety (Farrag and Saleh 1996; Lodish et al. 2004; Toshihiro et al. 2006).

The production of sachet water started in the early 1990s and it's general it consumption has been very among the poor and low-income individual in Nigeria. The production, packaging and distribution of sachet water has been reported to be prone to microbial contaminated (Oyedeji et al. 2010; Onilude et al. 2013; Balogun et al. 2014). This work was aimed at evaluating the effects of gamma radiation on survival and antibiotic susceptibility pattern of two water indicator organisms: Enterococcus faecalis and Escherichia coli introduced into sachet water.

\section{MATERIALS AND METHODS}

\section{Sources and standardization of test organisms}

The two test bacteria were collated from the Department of Microbiology, Ekiti State University, Nigeria. The identity of the isolates was confirmed by biochemical tests. Enterococcus faecalis was plated on Bile aesculin azide agar (Oxoid) and incubated at $37^{\circ} \mathrm{C}$ for 24 h. Production of the black halo was looked for after the incubation. Gram reactions and the ability of the isolate to utilize arabinose, inulin, lactose, mannitol, raffinose, sorbitol and sucrose were also determined. Escherichia coli was plated on Eosine Methylene Blue Agar (LAB M, UK) and incubated at $37^{\circ} \mathrm{C}$ for $24 \mathrm{~h}$. The plates were observed for a greenish metallic sheen. Biochemical methods which include Gram reactions, indole, Voges-Proskauer, and MethylRed test, utilization of citrate, fermentation of carbohydrate (arabinose, fructose, galactose, inositol, mannitol, mannose, rhamnose, ribose, sorbose and xylose) were carried out. The results were interpreted according to Holt et al. (1994).

\section{Preparation and introduction of indicator organisms into the water sample}

The broth cultures of each of the test bacteria were centrifuged at $3000 \mathrm{rev} / \mathrm{min}$ for $5 \mathrm{mins}$ after which it was decanted and washed twice with sterile distilled water and re-centrifuged at the same condition and decanted. The suspension of the washed cells was standardized according to Bauer et al. (1966).

\section{Inoculation of water samples for irradiation}

A $500 \mathrm{ml}$ of autoclave sterilized water sample was aseptically dispensed into sterile polythene sachets and approximately $1.7 \times 10^{7} \mathrm{CFU} / \mathrm{mL}$ of the test organism was introduced. The inoculated water sample was serially diluted and plated on McConkey and Bile aesculin agars and incubated at $37^{\circ} \mathrm{C}$ for $24 \mathrm{~h}$. to enumerate $E$. coli and Ent. faecalis loads respectively. The sachets of inoculated water samples were radiated by the cobalt-60 machine (gamma radiation) at a field size of $25 \mathrm{~cm} \times 20 \mathrm{~cm}$ and depth of $2 \mathrm{~cm}$ with varying doses.

\section{Detection of bacterial load in the sample}

Loads of the test organisms in both irradiated and non-irradiated water samples were determined over a period of 10 days. Daily one milliliter of the water samples was inoculated on Nutrient Agar (Oxoid) and incubated for $24 \mathrm{~h}$ at $37^{\circ} \mathrm{C}$ and the number of colonies developed on the plates was counted and recorded. This was carried out in triplicate and experiment repeated twice.

\section{Antibiotics susceptibility testing}

One milliliter from the water samples was introduced separately into Eosin Methylene Blue and Bile aesculin azide agars to re-isolate E. coli and Ent. faecalis respectively. The colonies with distinct characteristics of the test bacteria were picked and sub-cultured. Broth of each of the organisms was standardized to 0.5 Mac-Farland standards and seeded separately on sterile Mueller-Hilton agar (Oxoid) plates. The disc diffusion method was used to assess the susceptibility of the isolates as described by the Clinical and Laboratory Standard Institute (CLSI 2012). The isolates were tested against the following different antibiotics (Abtek Biologicals Limited) with their concentrations in microgram: Ampicillin [AMP (10)], Clindamycin [CLN (2)], Clotrimazole [CLT (10)], Colistin [COL (2)], Cotrimoxazole [COT (25)], Erythromycin [ERY (5)], Fusidic acid [FUS (10)], Gentamycin [GEN (10)], Penicillin [PEN (10)], Streptomycin [STR (10)], Sulphamethaxazone [SMX (15)], Sulpholurazole [STD (200)], Tetracycline [TET (25)] and Trimethoprim [TRM (25)]. 


\section{RESULTS AND DISCUSSION}

The antibiotics susceptibility pattern of $E$. coli before, and after irradiation was presented in Table 1. Gamma radiation affected E. coli resistance to CPL, GEN and STR. The organism was not inhibited by the antibiotics after exposure to 2, 3 and $4 \mathrm{gy}$. The zone of inhibition was slightly shown after exposure to 5 gy. While Ent. faecalis had a lower zone of inhibition when exposed to CLN, ERY, FUS, and GEN. On the other hand, SMX and TRM had a higher inhibitory effect on the isolates after exposure to $5 \mathrm{gy}$. His trend is similar to the report of Meckes (1982).
The results showed Ent. faecalis to be resistant to all the antibiotics tested after exposure to a dose rates of 2 gy and 3 gy (Table 2). At dose rate of $5 \mathrm{gy}$, the organism was sensitive to all the antibiotics except penicillin. After irradiation Ent. faecalis produced a lower susceptibility to most of the antibiotics. This is at variance with the report of Eman (2003) who reported that enteric bacteria were susceptible to tetracycline and ampicillin after irradiation. In a similar trend, Yahia et al. (2015) reported that gamma irradiation increased the sensitivity of Salmonella to different antibiotics.

Table 1 Antibiotic susceptibility profile of $E$. coli before and after irradiation (zone of inhibition in $\mathrm{mm})$

\begin{tabular}{llllll}
\hline & & \multicolumn{5}{l}{ After irradiation (gy) } \\
\cline { 3 - 6 } Antibiotics & Before & $\mathbf{2}$ & $\mathbf{3}$ & $\mathbf{4}$ & $\mathbf{5}$ \\
\hline AMP & 0 & 0 & 0 & 0 & 0 \\
CLT & 0 & 0 & 0 & 0 & 0 \\
COT & 0 & 0 & 0 & 0 & 0 \\
CPL & 9 & 0 & 0 & 0 & $1.3 \pm 1.0$ \\
GEN & $11.3 \pm 2.3$ & 0 & 0 & 0 & $1.7 \pm 1.0$ \\
STD & 0 & 0 & 0 & 0 & 0 \\
STR & $10.2 \pm 1.6$ & 0 & 0 & 0 & 0 \\
TET & 0 & 0 & 0 & 0 & $1.2 \pm 0.3$ \\
\hline
\end{tabular}

COL-Colistin, GEN-Gentamycin, STR-Streptomycin, STD-Sulpholurazone, TET-Tetracycline, COT-Cotrimoxazole, AMP-Ampicillin, CLT-Clotrimazole

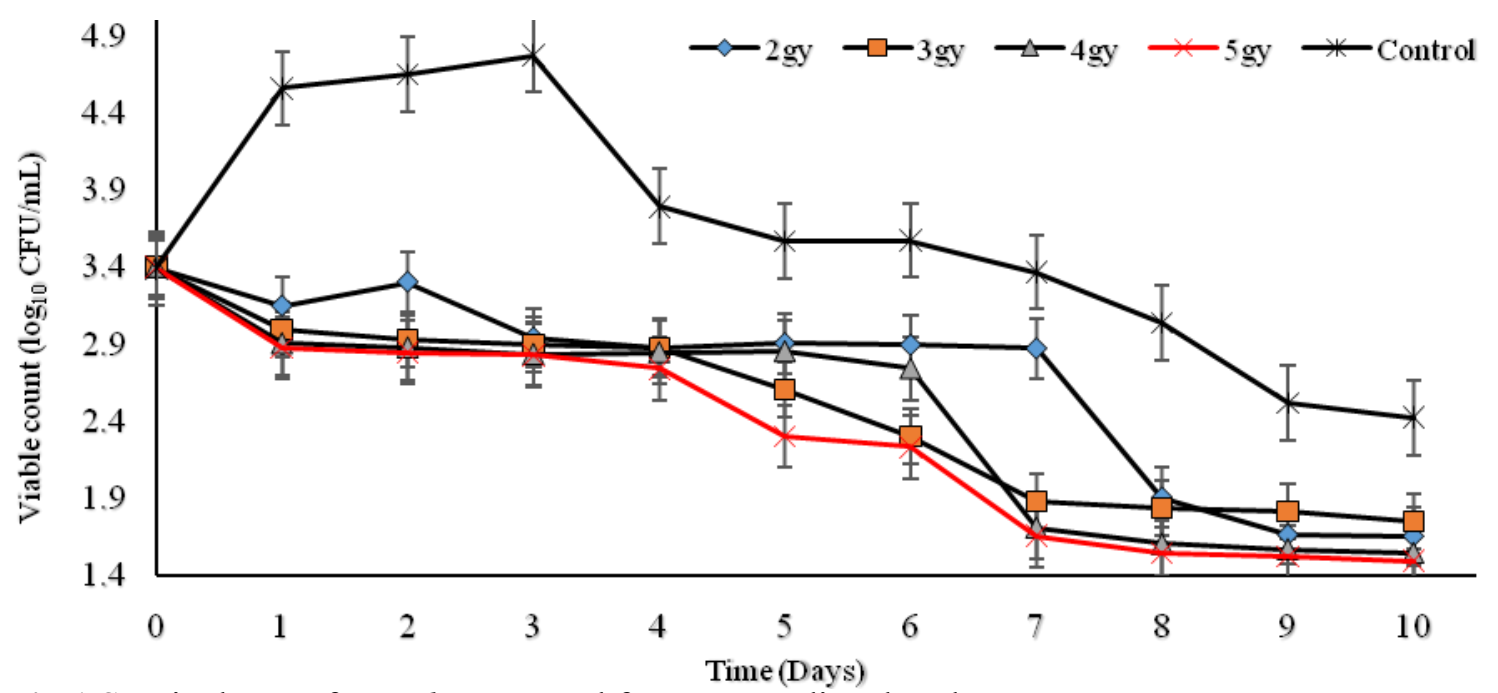

Fig 1 Survival rate of $E$. coli recovered from non-radiated sachet water 
Table 2 Antibiotic susceptibility profile of Enterococcus faecalis before and after irradiation (zone of inhibition in $\mathrm{mm}$ )

\begin{tabular}{llllll}
\hline & & \multicolumn{5}{l}{ After irradiation (gy) } \\
\cline { 3 - 6 } Antibiotics & Before & $\mathbf{2}$ & $\mathbf{3}$ & $\mathbf{4}$ & $\mathbf{5}$ \\
\hline CLN & $6.1 \pm 2.5$ & $0.5 \pm 0.1$ & 0 & 0 & $2.5 \pm 1.2$ \\
ERY & $4.6 \pm 1.0$ & 0 & 0 & 0 & $2.2 \pm 1.0$ \\
FUS & $9.3 \pm 1.4$ & $1.5 \pm 1.0$ & 0 & $1.8 \pm 0.2$ & $3.6 \pm 1.4$ \\
GEN & $8.4 \pm 2.0$ & $1.3 \pm 0.2$ & 0 & 0 & $1.9 \pm 0.2$ \\
PEN & 0 & 0 & 0 & 0 & 0 \\
SMX & 0 & 0 & 0 & 0 & $2.7 \pm 1.0$ \\
TET & $2.6 \pm 1.4$ & 0 & $1.9 \pm 0.1$ & $1.5 \pm 0.2$ & $2.9 \pm 1.0$ \\
TRM & 0 & 0 & 0 & $2.2 \pm 0.1$ & $2.1 \pm 1.0$ \\
\hline
\end{tabular}

GEN-Gentamycin, FUS- Fusidic acid, TRM-Trimethoprim, SMX-Sulphamethaxazone, TET-Tetracycline, PEN-Penicillin, ERY-Erythromycin, CLN-Clindamycin

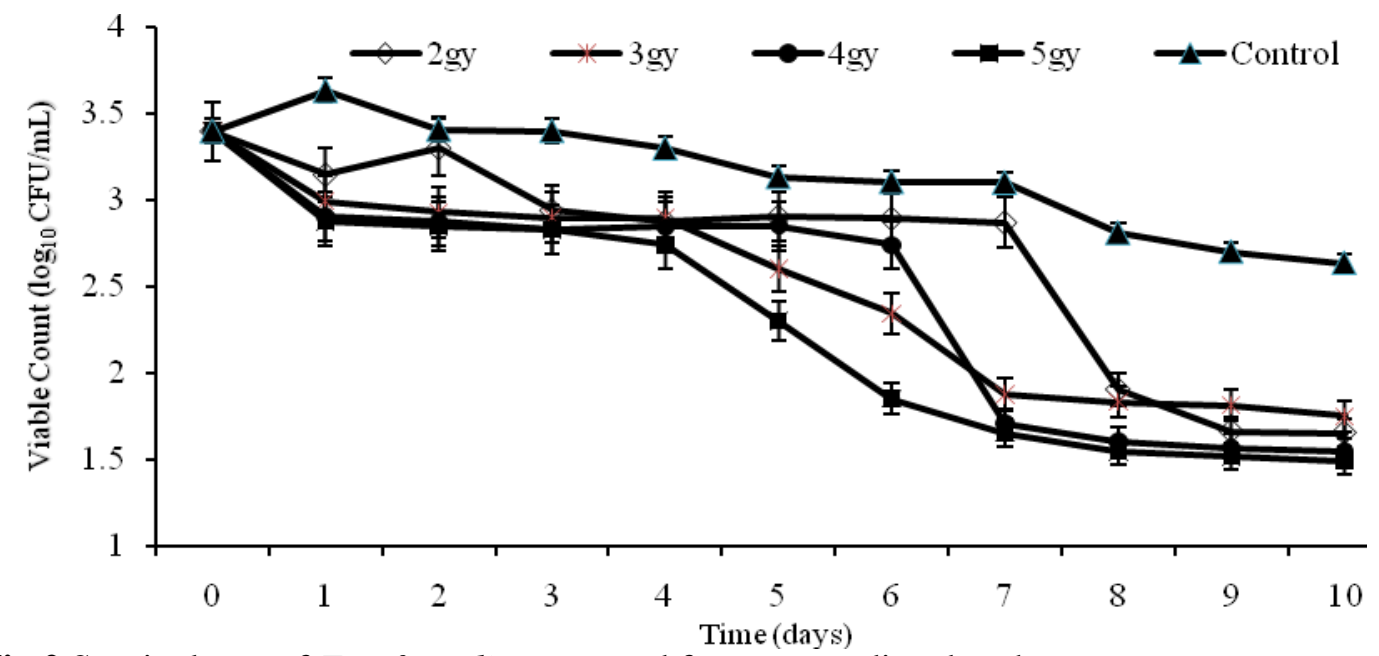

Fig 2 Survival rate of Ent. faecalis recovered from non-radiated sachet water

Abojassim et al. (2016) reported the presence of a significant positive correlation between gamma irradiation and inhibition of different types of pathogenic bacteria. The reduction in bacterial susceptibility may be due to chromosomal exchange or mutation (Johnson et al. 2006; Amyes 2007; Mundy et al. 2000). Also, water serves as possible vectors of strain transmission to human intestinal flora (Witte 2000; Salyers 2004). After irradiation, the viability for both $E$. coli and Ent. faecalis decreased at a dosedependent rate compared with the control. This agreed with the result of Tuncayciumus et al. (2008) who reported low bacterial load in meatballs challenged with E. coli and Ent. faecalis after gamma radiation. Gamma radiation induces the DNA by interfering with the genetic material causing the variety of changes and breaks in DNA strands (Rothkamm 2003; Lodish et al. 2004; Prescott et al. 2008) thereby making the organisms either resistant or susceptible after irradiation (Lodish et al. 2004).
The ability of the ray to cause permeability of ionic channels in the bacterial membrane, damage of DNA and impairment of efflux pump systems have been reported to be mechanisms of action of gamma ray (Berrier et al. 1993; Farrag and Saleh 1996; Galvanoskis et al. 1999; Pouget et al. 1999; Yahia et al. 2015). Figures 1 and 2 show the survival time of $E$. coli and Ent. faecalis respectively. After irradiation, the viability of both E. coli and Ent. faecalis decreased gradually as time increased. The effect of the irradiation on the E. coli and Ent. faecalis was dose-dependent. Abo-State et al. (2014) reported that the pathogenic bacteria strains isolated from water showed no growth after exposure to irradiation. The total aerobic mesophilic count has been reported to be lower after exposure to gamma-ray (Pouget et al. 2002; Zafer and Gurbuz 2007). 


\section{CONCLUSION}

Gamma radiation reduced the population of the test organisms in the water sample but does not positively affect their susceptibility to antibiotics. The exposure of the sachet water to irradiation before the final packaging will further reduce the bacterial contamination and subsequently waterborne infections.

\section{ACKNOWLEDGEMENT}

The authors acknowledge the contribution of Mr. S.S. Ajayi of the Department of Microbiology, Ekiti State University, Ado-Ekiti, Nigeria for his technical assistance.

\section{REFERENCES}

Abojassim, A.A., Hassan, B.A., Al-Gazaly, H.H. and Saleh, N. 2016. Effect of gamma irradiation on some types of pathogenic bacteria. Research Journal of Pharmaceutical, Biological and Chemical Sciences 7(3): 1349-1353.

Abo-State, M.A., El-Gamal, M.S., El-Danasory, A. and Mabrouk, M.A. 2014. Radio-Impact of Gamma Radiation on Pathogenic Bacterial Strains Isolated from Rosetta Branch and its Drains of River Nile Water. Middle-East Journal of Scientific Research 21(5): 776-781.

Akelah A. 2013. Functionalized Polymeric Materials in Agriculture and the Food Industry. Pp 242. Springer Science Business Media, New York.

Ambulkar, A. 2015. Guidance for Professional Development in Drinking Water and Waste Water Industry. Pp 57. International Water Association Publisher, UK.

Amyes, G. 2007. "Enterococci and Streptococci". International Journal of Antimicrobial Agents 29: 43-52.

Ansari, A. 2009. Radiation Threats and Your Safety: A Guide to Preparation and Response for Professionals and Community. Pp. 310. Taylor and Francis/CRC Press, Boca Raton, Florida.

Balogun, S.A., Akingbade, O.A., Oyekunle, M.A. and Okerentugba, P.O. 2014. Physicochemical and microbiological profile of drinking water sold in Abeokuta, Ogun State, Nigeria. Nature and Science 12(3): 103-105.

Bauer, A.W., Kirby, W.M.M., Sherris, J.C. and Turck, M. 1966. Antibiotic susceptibility testing by a standardized single disk method. American Journal of Clinical Pathology 36: 493-496.
Berrier, C., Coulombe, A., Houssin, C. and Ghazi, A. 1993 Voltage-dependent cationic channel of Escherichia coli. Journal of Membrane Biology 133: 119-27.

Clinical and Laboratory Standards Institute 2012. Performance standards for antimicrobial disk susceptibility tests, approved standards $11^{\text {th }}$ ed. CLSI document M02-A11. Clinical and Laboratory Standards Institute. Wayne, PA.

Eman, Y.T. 2003. Effect of gamma irradiation, antibiotic, essential oil and heat treatment on Salmonella typhimurium. Journal of Essential Oil Research 12: 639-649.

Farmer, J. J. 2003. Enterobacteriaceae: Introduction and Identification. Manual of Clinical Microbiology 69: 5306-5318.

Farrag, A.H. and Saleh, M.A. 1996. Changes in DNA content, Ploidy content and radio sensitivity before and after test dose radiation in some microorganisms isolated from urinary transitional carcinoma. Egyptian Journal of National Cancer Institute 8: 213-224

Galvanoskis, J., Sandblom, J., Bergqvist, B., Galt, S. and Hammerius, E. 1999. Cytoplasmic $\mathrm{Ca}^{++}$oscillation in human leukemia T-cells are reduced by $50 \mathrm{~Hz}$ magnetic field. Bioelectromagnetics 20(5):269-276.

Gross, L. 2007. Paradox resolved the strange case of the radiation resistant bacteria. Plos Biology 4: 1-2.

Jin, G., Jeng, H.W., Bradford, H. and Englande, A. J. 2004. Comparison of Escherichia coli, enterococci and faecal coliforms as indicators for brackish water quality assessment. Water Environment Respiration 76(3): $245-255$.

Johnson, J., Kuskwoski, M., Menard, M., Gajewski, A., Xercavins M. and Garau, J. 2006. "Similarity between human and chicken Escherichia coli isolates in relation to ciprofloxacin resistance status. Journal of Infectious Diseases 194(1): 71-78.

Kelly, K. 2005. Radiation may have positive effects on health: study low chronic doses of gamma radiation had beneficial effects on meadows voles. http://www.epa.gov/rpdvebro/understand/io nize_nonionize.html.Accessed on 2010-0509.

Lodish, H., Berk, A., Matsudaira P., Keuser, C. A., Krieger, M., Scott, M. P., Zipursky, S. L. and Darnell, J. 2004. Molecular biology 
of the cell. $5^{\text {th }}$ ed. Pp 963. Freeman and Co. Publisher. New York.

Meckes, M.C. 1982. Effect of UV light disinfection on antibiotic-resistant coliform in wastewater effluents. Applied Environmental Microbiology 43(2): 371377.

Mote, B. L., Turner, J. W. and Lipp, E. K. 2012. Persistence and growth of the faecal indicator bacteria enterococci in detritus and natural estuarine plankton communities. Applied and Environmental Microbiology. 78(8): 25692577.

Mundy, L.M., Sahn, D.F. and Gilmore, D. 2000. Relationships between enterococcal virulence and antimicrobial resistance. Clinical Microbiological Review 13: 513-522.

Onilude, A.A., Adesina, F.C., Oluboyede, O.A. and Adeyemi, B.I. 2013. Microbiological quality of sachet packaged water vended in three Local Governments of Oyo State, Nigeria. African Journal of Food Science and Technology 4(9): 195-200.

Oyedeji, O., Olutiola, P.O. and Moninuola, M.A. 2010. Microbiological quality of packaged drinking water brands marketed in Ibadan metropolis and Ile - Ife city in South Western Nigeria. African Journal of Microbiology Research 4: 96-102.

Pouget, J.P., Frelon, S., Ravanat, J.L., Testard, I., Odin, F. and Cadet, J. 2002 Formation of Modified DNA Bases in Cells Exposed either to Gamma Radiation or to High-LET Particles. Radiation Research 157(5): 589595.

Pouget, J.P., Ravanat, J.T., Douki Richard, M.J. and J. Cadet, J. 1999. Measurements of DNA base damage in cells exposed to low doses of gamma radiation: comparison between HPLC-EC and comet assays. International Journal of Radiation Biology 75: 51-58.

Prescott, L. M., Harley, P. J. and Klein, A. D. 2008. Microbiology. The proteobacteria $.7^{\text {th }}$ ed. Pp 558 - 585,851. McGraw Hall Publisher. Singapore.

Rothkamm, K. 2003. Evidence for lack of DNA strand break repair in human cells exposed to very low x-ray doses. National Academy of Science of the USA 100(9): 5057-5062.

Salyers, A.A., Gupta, A. and Wang, Y. 2004. Human intestinal bacteria as reservoirs for antibiotic resistance genes. Trends in Microbiology 12(9): 412-416.
Sharon-Palmer, R.D. 2009. Irradiation: What it is, what it does, and how it affects the food supply. Today's Dietitian 11(1): 32

The Council of the European Union (CEU) 1998. Council Directive 98/83/EC of 3 November 1998 on the quality of water intended for human consumption. European Union.

Toshihiro, O. and Shin-Ichi, T. 2006. UV Sensitivity and Mutagenesis of the extremely Thermophilic Eubacterium Thermus thermophilus HB27. Genes and Environment 28(2): $56-61$.

Tuncaycimus, A., Sukuru, D., Murat, V., Serap, D. V., Ismail, Y. and Osman, S. 2008. Application of Gamma Radiation for inactivation of three pathogenic bacteria inoculated into meatballs. Radiation Physics and Chemistry 77: 1093 - 1096.

Wheeler, A. L., Hartel, P. G., Godfrey, D. G., Hill, J. L. and Segars, W. I. 2002. Potential of Enterococcus faecalis as a human faecal indicator for microbial source tracking. Journal of Environmental Quality. 31(4): 1286-1293.

Witte, W. 2000. Ecological impact of antibiotic use in animals on different complex microflora. Environmental International Journal of Antimicrobial Agents 14: 321-325.

Yahia, N.B.M., May, A.E., Helel, S., Maatouk, I., Chatti, A., Saidi, M. and Landoulsi,A. 2015. Gamma irradiation increases the sensitivity of Salmonella to antibiotics. International Journal of Science and Technology 4(6): 279288.

Zafer, G. and Gurbuz, G. 2007. Influence of Gamma radiation on growth and survival of Escherichia coli 0157:H7 on quality of cig kofte, a traditional raw meat product. International Journal of Food and Science Technology 42: $1067-10$ 